\title{
INTEGRATED GIS SYSTEM FOR POST-FIRE HAZARD ASSESSMENTS WITH REMOTE SENSING
}

\author{
V. Barrile ${ }^{1}$, G. Bilotta ${ }^{1,2}$, A. Fotia ${ }^{1, *}$, E. Bernardo ${ }^{1}$ \\ ${ }^{1}$ DICEAM - Department of Civil, Energy, Environmental and Material Engineering, "Mediterranea" University of Reggio Calabria, \\ Via Graziella Feo di Vito 89122 Reggio Calabria, Italy - (vincenzo.barrile, antonino.fotia, ernesto.bernardo)@unirc.it \\ ${ }^{2}$ Dept. of Planning, University IUAV of Venice, Santa Croce 191 Tolentini, 30135 Venice, Italy - giuliana.bilotta@iuav.it
}

\section{Commission IV}

KEY WORDS: Fires, Remote Sensing, Object Based Image Analysis, Structural analysis, GIS

\begin{abstract}
:
Fires continue to devour hundreds of thousands of hectares of forest even in 2020, generating gigantic damage to the ecosystem, if we think that we are in the midst of a climate crisis caused precisely by $\mathrm{CO} 2$ emissions into the atmosphere by man, due to burning of fossil fuels. The action to safeguard the territory and the fight against its progressive environmental degradation focus a great attention towards forest fires, also considering the enormous environmental damage that these have caused to important and very large areas of the globe. The aim of the contribution that we here propose is the design and implementation of a software tool that performs predictive functions of triggering possible forest fires, thanks to the integration and manipulation of data from different sources and processed by predictive mathematical models, to support decisions; the comparison of techniques for the processing of high-resolution remote sensing data from optical satellites for the best automatic discrimination of the areas covered by fire plays a fundamental role in the analysis. This allows managing the burnt areas also considering subsequent fire risks, and the integration of the techniques developed in a GIS in order to obtain an accurate perimeter and a fire risk map prevision.
\end{abstract}

\section{INTRODUCTION}

In the modern era, where the impact of human activity on planet Earth is so intense and the protected areas play an important role in maintaining biodiversity and ecological processes. The main strategy used to know the wildfires regimes is the systematized record of occurrences, which is accomplished through the completion of a document called Fire Occurrence Records.

In addition, fires in PAs can also be detected and evaluated by remote sensing data. Fire regimes can be characterized by the spatial pattern, the affected area, frequency, seasonality, intensity and severity (Lentile et al., 2006). These characteristics can be identified with RS data, observing the resolutions (spatial, temporal, radiometric and spectral) of the sensor systems used. Sensors with short revisit cycle are interesting for the detection of heat sources (active fire) (Csiszar et al., 2014). In addition, sensors with smaller pixels, such as the Landsat series $(30 \mathrm{~m})$, are suitable for determining the extent of the burned area and the monitoring of post-fire effects (Daldegan et al., 2014). However, thanks to the large number of satellites, the multisensor data enable both the detection of the active fire front and the effects of fire passage and their characterization.

\subsection{Paper's Objective}

In order to create a Fire predictive system, to prepare the different layers to use one the GIS in our work, we propose Object Based Image Analysis (OBIA) methods applied to the detection of burnt areas. The OBIA methodology, as is well known, is structural and differs from classic methodology of spectral analysis; in land use classes, indeed, pixel-based analysis enhances ambiguity in their statistical definition as the resolution increases in remotely sensed images. The described problem is reduced with the techniques of multi-resolution segmentation and fuzzy classification. With extensive analysis on objects, it is in fact possible to enrich and improve the information obtained from remote sensing data, obtaining, among other things, immediate integration into GIS. A decision tree was also used which takes into account the indices known in the literature (Number Digital Vegetation Index NDVI, Normalized Burn Ratio NBR etc.) in order to improve the results obtained.

The main objective of the project is to draw up the perimeter of the areas covered by fires through an organic and continuous information process. It is generated both through the homogenization of the specific databases on the topic and through the acquisition of all the data necessary for the preparation and system management through the relevant tools made available by today's Geomatics technologies and resources, and mainly Remote Sensing.

The final aim of the project is therefore to create a complete Integrated Fire System in which the forest fire event will be known in relation to the registration of the maps, the geometric data of the burned area, the level of damage, coming to make an estimate of the carbon lost following the passage of the fire.

\subsection{Methodological approach}

Based on what we said, a highly flexible and separate methodology has been implemented for the two training and updating moments envisaged by the regulations: the first is inherent in the preparation of the fire system based on historical information, the second relates to updating the system. Particular attention we paid to updating from satellite data, characterized by a high degree of accuracy and timeliness of information based on very high-resolution satellite images.

\footnotetext{
* Corresponding author
} 


\section{THE INTEGRATED FIRE SYSTEM}

In most cases, man is who triggers the fires, in a more or less intentional way. Predicting and preventing a fire is therefore impossible. We can, however, know in advance which areas are most at risk and how a fire will behave when it starts: how far the front of the fire will be, in which direction and how quickly it will move. Science has made great strides: today several forecasting models allow to elaborate risk maps with a high level of detail on the territory. Most of these models process various information. First of all the weather data: temperature, rainfall and above all wind intensity and direction, which plays a decisive role in the management of a fire; then information on the type of vegetation, its humidity and the slope of the area.

All these data, translated into a map, allow local authorities to plan interventions. Where could more men and means serve? Will the ground teams suffice or will airplanes also be needed? Above all, how many forces will be needed?

Part of the system collects historical data. At each historical point of fire start the data on altitude, slope and its orientation, dominant wind, extension, nature of the terrain and any crops, time spent for extinguishing, number of men and vehicles, including aerial (planes or helicopters), and tools used by the Fire Department, including the cause identified.

The goal is the design and implementation of a software tool that performs predictive functions of triggering possible forest fires, thanks to the integration and manipulation of data from different sources and processed by predictive mathematical models, to support decisions.

The system to be implemented includes a DEM as a base and must process weather data including temperatures, information on the orography and type of vegetation.

This allows in real time to obtain information on atmospheric, meteorological, environmental, territorial variations, and to control the evolution or development of fires.

Mitigating the risk factor, the safety of operators in the field, the proactivity in conveying information with the control rooms of crisis operations, must naturally involve firefighters, civil protection and national authorities.

The functions charged to the system are:

- Risk planning and analysis: Simulation in the geographic areas of fires, evolution of the flame front, evaluation of the means available and of the surrounding variations for the extinguishing operations.

- Emergency management: Identification of fumes, heat and direction to coordinate shutdown operations and containment of environmental and civil damage. Ease of communication between the parties involved and real-time updating of data collection in the field.

- Early Warning: Through the WEB platform and the Mobile application, the system must provide alerts to sector operators, reports sent to the system by civilians (including data collected from social networks), and changes in the status of data collected in real time.

Among the most important phases are of course the design of the logical-conceptual model of the Integrated System infrastructure, the homogenization of the databases and the implementation of the data entry in order to build the definitive database in PostGIS format. The spatial component (survey geometry) is obtained directly from the databases in which the surveys carried out by the Fire Brigade are reported. The spatial localization of the areas covered by the fire allows, among other things, an exact correspondence with the information of the cadastre of the vectorised properties, georeferenced and inserted in the Geodatabase.

The third phase includes statistical analysis of data with advanced techniques of dynamic creation of self-updating reports on analyses such as, among others, those relating to the frequency of fires per month, per day and hour, due to ignition, duration of the fires. The system is therefore able to also performing spatial statistical analyses in order to refine the analysis of environmental - territorial variables, investigating the spatial relationships between environmental factors (essentially morphology, vegetation, land use) with the occurrence of the forest fire phenomenon. Are so investigated frequency of fires by class of slope, by altimetric class, by exposure of the slope, by forest category, by category of land use, by distance from roads and from inhabited centres or nuclei and others, all analyses that constitute the knowledge base for the creation of the fire risk card. In addition to providing print reports on static (alphanumeric and spatial) analyses, the system is able to manage the printing of the particles affected by the fire with related documentation useful for official publication by the local authorities.

\subsection{Update of the fire register}

Established the basic infrastructure of the system with the starting data system and the management and storage infrastructure of the same, it follows the phase of updating the cadastre and therefore of the complex system proposed.

The updating of the fire register consists of detecting the areas covered by the fire as events occur or in any case in times useful for the exact identification of the perimeter of the territorial portion covered by the fire (Italscar, 2003) (Chirici et al., 2003) (Marzano, Bovio, 2004) (Mitri, Gitas, 2006).

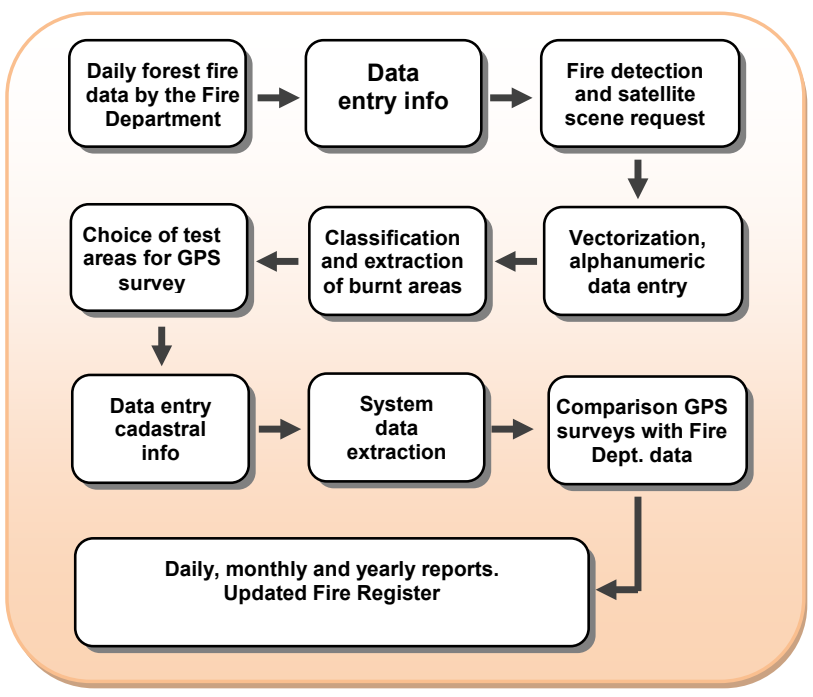

Figure 1. Remote sensing update flow chart

Various are possible intervention processes for the system update phase. These differ according to the different data acquisition methods, but the hypothesis of updating the system through the acquisition and classification of the images satellite, as mentioned above, is the desired solution as it is characterized by a high degree of accuracy and timeliness of information and is also capable of achieving a better cost/benefit ratio. With the same information equipment - very high resolution satellite images - it will also be possible to carry out further studies useful for monitoring and updating sector information such as land use (Bilotta, 2005), (Barrile. Bilotta 2007a, 2007b), illegal landfills, (Barrile et al., 2013) asbestos coverage (Barrile et al., 2008), riverbeds, map updates, environmental pollution. In addition, another important aspect of assessing the damage to 
vegetation and estimating $\mathrm{CO}_{2}$ emissions due to the passage of the forest fire becomes executive.

The planned calculations are based on the analysis of satellite images of different origin and nature (Landsat, Ikonos), with the realization of processing adapted to the identification of areas already affected by fires. A multi-temporal analysis is carried out for this purpose by the multispectral sensor data Enhanced Thematic Mapper $(\mathrm{ETM}+)$ of the Landsat7 satellite, with analysis of very high resolution images of the Ikonos satellite with the use of statistical techniques based on the NDVI (Number Digital Vegetation Index), on the NBR (Normalized Burn Ratio) . We also planned innovative techniques based on multi-resolution segmentation and on the creation of hierarchies of classes related to each other in order to achieve an adequate classification of the territory that correctly discriminates the areas reached by the fires.

The choice of the type of high-resolution satellite data is suggested by a series of considerations:

a) The size of the area to be analyzed: in fact, considering that the scope of analysis in general is a territory for the most part not densely urbanized.

b) The analysis allowed by Landsat datasets, although valuable for the availability of the near, medium and thermal infrared bands, proves insufficient both for the pixel dimensions and for the unavailability of reliable data following malfunctions of the Landsat 7, therefore, referring to very high-resolution data, such as those of the Ikonos satellite, was considered to be appropriate.

We implemented a methodology that use the integration of Landsat and Ikonos remote sensing data. The choice of both data is to be found in different reasons, especially the main objective of conducting an investigation on a space of considerable size, accurately, while limiting the cost. Landsat data is provided at a relatively low cost, compared to the vast utility it can make of it. For our case it is useful, since the object of analysis will be subjected to a classification procedure based on decision criteria (vegetation indices) that work in the near and medium infrared bands, and the Landsat data is one of the few available to have a certain variety of bands. However, there is an obligation to combine it with the Ikonos data which has one of its strengths in spatial resolution.
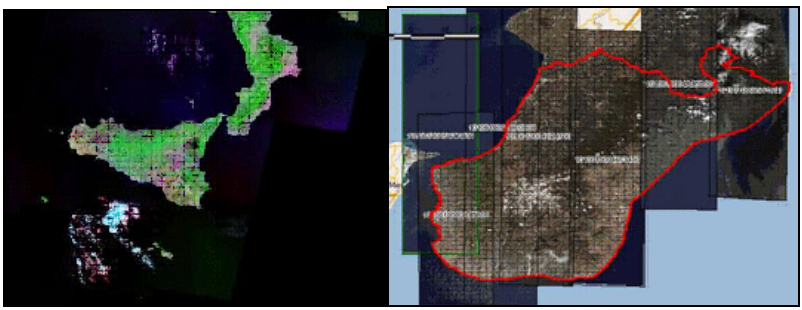

Figure 2, 3. Scenes Landsat and Ikonos available for the province of Reggio Calabria

Their merger results in a data that maintains the large number of spectral bands of the Landsat for the indices characterizing the subsequent classification procedure (Angiulli et al., 2005a, 2005 b), but at the same time presents a more accurate detail, due to the new spatial resolution inherited from the Ikonos data. By overlapping with a digital elevation model (DEM) relating to the area of interest, necessary to ensure adequate corrections about the topography of the data, it is also possible to define the slope and slope characteristics necessary to discriminate the situations of the areas covered by fire. The data thus obtained is subjected to a semi-automatic classification procedure, developed within the ENVI software; therefore, the complete analysis follows the following steps:
- Image acquisition;

- Classification aimed at highlighting areas covered by fires;

- Elaboration and synthesis through vegetation indices (NBR and $\mathrm{BAI})$.

The analysis conducted revolves around the processing of the classified image through the vegetation indexes NBR (Normalized Burned Ratio) and BAI (Burned Area Index).

These indices represent the decision criteria for making the differentiation on the image.

The NBR is sensitive to the damage caused by the fire on the vegetation while the BAI detects the deposition of the combustion remains after the fire.

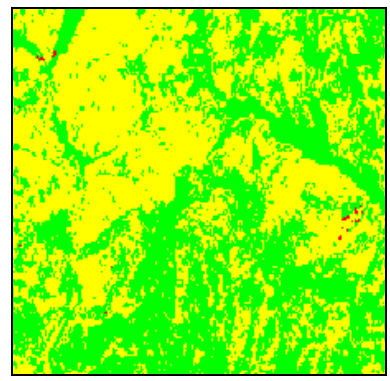

Figure 4. Discrimination of areas burned by the NBR in the decision tree

The two indices are calculated according to the following formulas:

$$
N B R=\frac{(N I R-S W I R)}{(N I R+S W I R)}
$$

where $\quad N I R=$ Near Infrared band

$S W I R=$ Short Wavelength Infrared band

$$
\begin{aligned}
& B A I=\frac{1}{(\text { REDrif }- \text { REDind })^{2}+(\text { NIRrif }- \text { NIRind })^{2}} \\
& \text { where } \quad \begin{array}{l}
R E D=\text { Red band } \\
N I R=\text { Near Infrared band }
\end{array}
\end{aligned}
$$

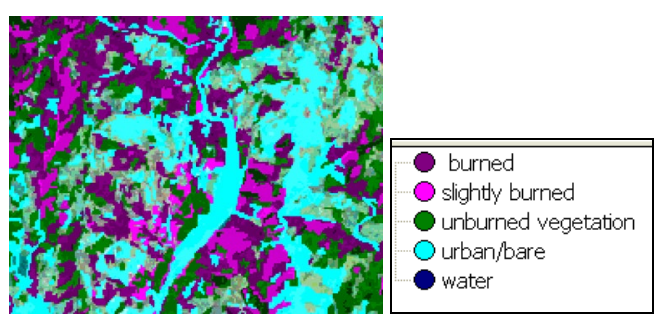

Figure 5. Classification of Landsat data in a highly compromised area - third level

\subsection{Object Based Image Analysis}

The tool used for OBIA (Baatz et al.,2004) organizes hierarchically and arranges data of different typologies as vector and raster data. It is possible to establish rules relating to the context; the relationships between the objects meaningfully enhance the automatic acknowledgment of the objects on the Earth's surface.

This manual photo interpretation approach, which obtains a subjective classification, allows a homogenous process that can be reproduced, thereby exceeding the problems of traditional classification techniques. The choice of the scale factor allows 
calibration of the size of the polygons obtained by segmentation, and its definition is linked to the obtained reference map scale.

Segmentation is defined as multiresolution because, starting from the same image, it is possible to obtain different hierarchical levels of polygons with various scale factors. By reducing the scale factor, the dimensions of the generated polygons progressively decrease; smaller dimensions show the spectral variability inside the polygons while increasing the scale factor. The peculiarity of multiresolution segmentation consists in the connection between the polygons of the hierarchical segmentation levels.

When a first level of polygons is created, it is possible to create $\mathrm{n}$ new higher or lower hierarchical levels. Polygons of lower hierarchical levels are always geometrically consistent with those of higher hierarchical levels; therefore, each lower polygon belongs only to one higher polygon. All the polygons of the different segmentation levels constitute a single database, in which all the connections between the polygons of the same or different hierarchical levels are present.

Therefore, for each polygon, the polygons that are in contact with (on the same hierarchical level), the polygons that constitute a possible lower hierarchical level, and the polygon in which it is contained in the eventual upper hierarchical level are all known.

In the OBJ approach, the classification phase acquires information from the segmentation phase, (shape, and scale of image objects, specific information). Classification incorporates semantic and contextual information that uses the attributes of image objects and the relationship between linked image objects.

The wanted geoinformation and the objects of interest are extracted in a step-by-step process through iterative cycles of processing and classification. Therefore, image objects are processing units that continuously change in terms of classification, mutual relationships, and shape. Similar to human processes of understanding images, this type of circular processing translates into a sequence of intermediate states, with growing classification differentiation and a growing abstraction of the original image information.

The main limit of the pixel-based analysis of satellite data is the acknowledgment of semantic low-level information, i.e., the amount of energy emitted by a single pixel, with the context not possessing any role. In object-based analysis, the semantic level increases; relationship rules are added that combine space, topological and statistical information, with the context therefore being defined. Recognition is based on concepts of mathematical morphology (Bianchin, Pesaresi, 1993) (Köppen et al., 1998) (Serra, 1998) (Soille, Pesaresi, 2002) (Benediktsson et al. 2003), which are applied to the image analysis and elements of fuzzy logic for the classification phase.

The first phase involves segmenting the entire scene on further levels. The multiresolution segmentation automatically creates vectorial polygons, which are extracted directly from the image in perfect coincidence with the overlapping on the raster. Subsequently, the final classification prepares an adapted hierarchy of classes while considering the relationships between the obtained levels of segmentation.

\subsection{Segmentation}

Multiresolution segmentation is a technique of merging regions from the bottom up, beginning with one-pixel objects. In the following steps, smaller image objects merge into larger objects. During this grouping process, the underlying optimization procedure minimizes the weighted heterogeneity $\mathrm{n}_{h}$ of the obtained image objects; while $n$ is the size of a segment, $h$ is an arbitrary definition of heterogeneity. To represent the smallest growth in defined heterogeneity, the adjacent image objects are joined together. When the increase exceeds the threshold set by the scale parameter, the entire process stops. From the sum of the standard deviations of spectral values in each layer we obtain color or spectral heterogeneity, where the exclusive minimization of spectral heterogeneity leads to image objects with fractally shaped borderlines or branched segments.

In highly structured radar data, this effect is even stronger. From every pixel of an image, the segmentation algorithm fuses adjacent polygons until the change in observable heterogeneity between the two original polygons and the newly generated polygon does not exceed the threshold defined by the customer (scale factor).

If the heterogeneity change already does not exceed the defined threshold, fusion is effectively achieved; otherwise, the two polygons do not join but remain separated, and the choice of scale factor calibrates the large sizes of the resultant polygons.

\subsection{Classification}

The program chosen for this application uses classification based on Fuzzy logic (see references: Barrile et al. 2006a, 2006b)

Fuzzy set theory (Tzeng, Chen, 1998), which was developed to deal with imprecise information, provides a more appropriate solution to this problem. In fact, it provides useful concepts and tools to deal with imprecise information, allowing each region to have partial and multiple membership of several classes. A region's membership grade function with respect to a specific class indicates to what extent its properties are akin to that class. The value of the membership grade varies between 0 and 1 , with values closer to 1 indicating the more that region belongs to that class.

Partial membership allows for information about more complex situations, such as cover mixture or intermediate conditions, to be better represented and utilized.

Fuzzy logic, in a certain way, emulates human thinking, even taking into account linguistic rules. Fuzzy classification systems are well suited to handling most vague aspects of remote sensing information extraction. Uncertainties are considered using fuzzy sets defined by membership functions. Instead of the binary "true" and "false," fuzzy logic allows for transitions between "true" and "false".

There are strict realizations of the logical operations "and" and "or". The output of a fuzzy classification system is a fuzzy classification, where the membership degree of each land cover or land use class is given for each object, thereby enabling detailed performance analysis and providing insight into the class mixture for each image object. This is a major advantage of soft classification. A fuzzy rule base is a combination of fuzzy rules, where the simplest fuzzy rules are dependent on only one fuzzy set. Fuzzy rules are "if-then" rules; if a condition is fulfilled, an action takes place.

We can define some rules: "if" feature $x$ has a low value, "then" the image object should be assigned to a specific land cover. In fuzzy terminology this would be written as follows: if feature $x$ is a member of fuzzy set low, then the image object is a member of land cover $W$. We can combine fuzzy sets to obtain advanced fuzzy rules. The results are very evident and assure independent sequence of logical combinations within the basic rule.

These values indicate the degree of assignment of the land use class. Fuzzy classification provides the ability that an object belongs to a class, while probability-based classification provides the probability that an object belongs to a class. Fuzzy classification (Zadeh 1965) (Barrile et al. 2006a, 2006b) with its strong analysis of performance of the set of classes, 
classification stability, and reliability, is based on a powerful approach to soft classification. The fuzzy classification returns significant inputs for the merging of information in current and future remote sensing systems with multi-data of different origin.

The first application using a multispectral image from Landsat 7 ETM + acquired on 13 July 2001 allowed burned areas to be defined with good results. An object-oriented set was obtained, where the four levels derive from various scale parameters $(5$, 10,23 , and 30). The weight of each of the six bands at every level was different. During the segmentation process, the whole scene was segmented, image objects were created based upon various editable criteria of homogeneity regarding shape and color.

In the classification at level one, the basic six classes are "water", "urban/bare ground", "slightly burned", "burned area", "unburned vegetation", "shaded areas", and were distinguished. All classes were classified based on membership functions for different shape and spectral features. A classification based on three classes is performed before classifying level two. No source there is for the classification of "water", with the scene showing land crossed by a dry "fiumara", that is a dry stream. Features consider contextual and spectral information.
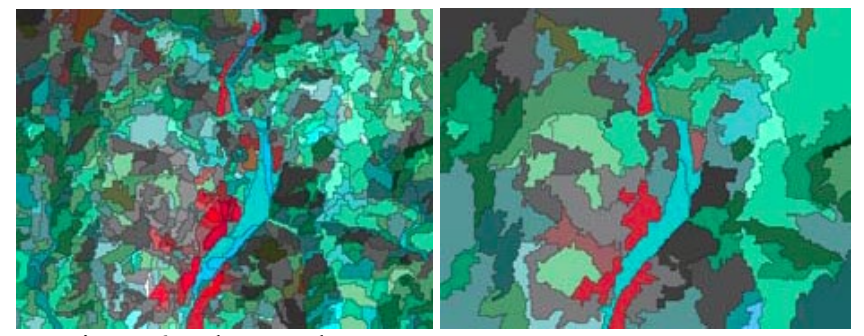

Figure 6 and 7. Landsat medium and coarse segmentation

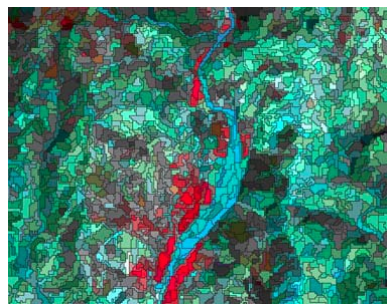

Figure 8. Landsat: fine segmentation
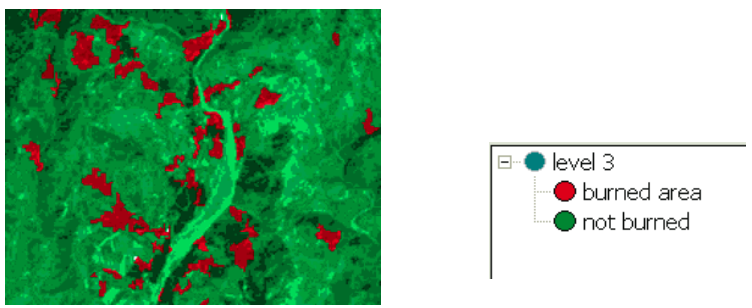

Figure 9. Landsat level 3 classification

In order to produce highly homogeneous objects in specific resolutions and for specific purposes, segmentation parameters were empirically determined, by adjusting and editing the scale parameters, band weights, shape, and color. The burned areas are more visible in bands 3 and 4 than in bands 1 and 2, so to bands 1 and 2 a "1" was assigned. All weights have a sum normalized to 1 .

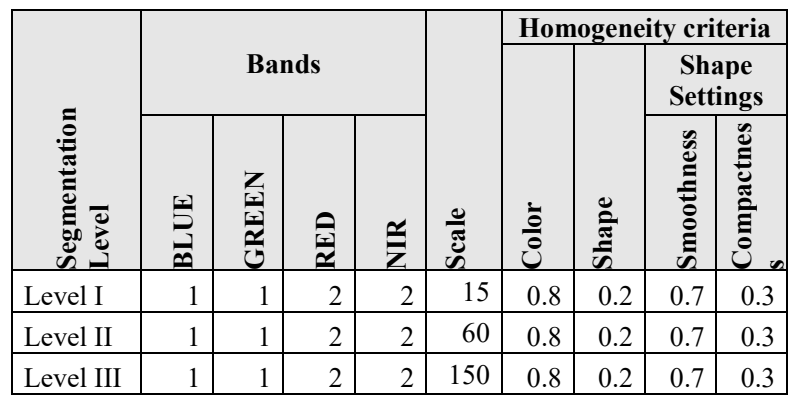

Table 1. Parameters for the segmentation of the Ikonos data

The segmentations were based on higher color factor $(80 \%)$ than the shape factor $(20 \%)$. The scale parameter is the limit for the maximum heterogeneity allowed to the obtained image objects.

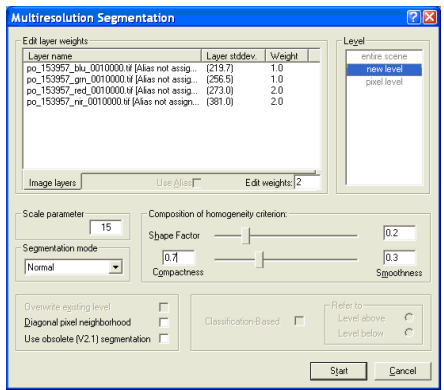

Figure 10. Ikonos, level 1: parameters for the segmentation

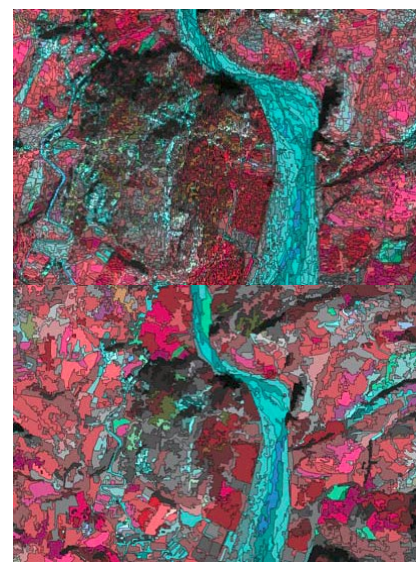

Figure 11 and Figure 12.. Ikonos image: first level (fine) of segmentation; Ikonos image: second level (medium) of segmentation 


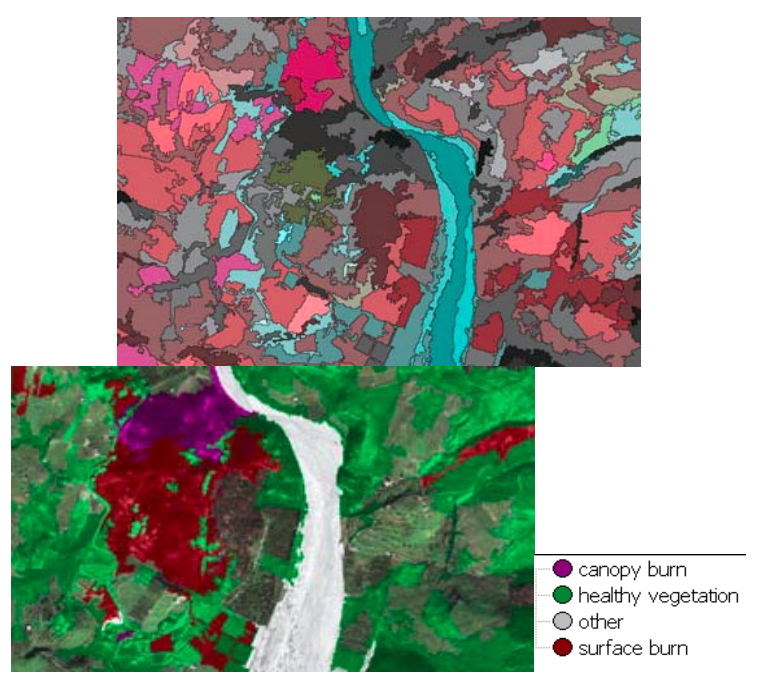

Figure 13 and Figure 14. Ikonos image: third level (coarse) of segmentation; Ikonos: classification

\begin{tabular}{|c|c|c|c|c|c|}
\hline & \multicolumn{4}{|c|}{ Algorithm } \\
\hline & & $\begin{array}{l}\text { Ground } \\
\text { truth }\end{array}$ & $\begin{array}{c}\text { Maximum } \\
\text { Likelihood }\end{array}$ & $\begin{array}{l}\text { Neural } \\
\text { Fuzzy Set } \\
\text { (Landsat) }\end{array}$ & $\begin{array}{l}\text { Neural } \\
\text { Fuzzy Set } \\
\text { (Ikonos) }\end{array}$ \\
\hline \multicolumn{2}{|c|}{ Overall Accuracy } & & $84.6320 \%$ & $95.6284 \%$ & $97.2678 \%$ \\
\hline \multicolumn{2}{|c|}{ Unclassified } & $0 \%$ & $4.9704 \%$ & $4.4816 \%$ & $3.2327 \%$ \\
\hline \multirow{2}{*}{ 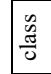 } & Surface burn. & $100 \%$ & $55.2540 \%$ & $60.2573 \%$ & $73.0451 \%$ \\
\hline & other & $100 \%$ & $67.9406 \%$ & $68.2612 \%$ & $75.7425 \%$ \\
\hline \multicolumn{2}{|r|}{ Total classified } & & $95.0296 \%$ & $95.5184 \%$ & $96.7673 \%$ \\
\hline
\end{tabular}

Table 2. Classification results

\section{IMPLEMENTATION OF THE SYSTEM}

The regional scale forest fire hazard map is very important in order to properly allocate fire prevention resources. The aim is therefore to create a system that can identify areas subject to fire hazard.

The various cartographic databases are therefore indispensable to share the risk fire knowledge.

The GIS system thus created is made available to all citizens as a tool for disseminating geographic information that allows the management both of the risk probability of certain areas, and both cartographic research.

Nowadays, the process of deforestation is also fuelled mainly by fires that transform the landscape. This fires, once triggered by natural or anthropic causes, spread very quickly, having a strong impact on safety, health and above on all the local economy.

It is, therefore, clear that a mapping of areas subject to fire hazard is extremely useful to track and predict any possible propagation, helping local authorities to establish where the resources have to be destined to fight and prevent them.

For this purpose, we used a different method to define the spatial prediction model of forest fire based on two training algorithms (implemented into the designed system): backpropagation and metaoreuristics. In this way, metaoreuristics avoid the fast convergence and the backpropagation helps the integrated algorithm to make better use of the search space.

The designed system use as input ten different parameters (to establish areas at risk, and to predict the fire propagation) related to climate, vegetation, topography and human activities that influence the occurrence of forest fires (slope $\left(^{\circ}\right.$ ), appearance, height (m), land use, NDVI, distance from the residential area $(\mathrm{m})$, distance from road $(\mathrm{m})$, precipitation $(\mathrm{mm})$, temperature $\left({ }^{\circ} \mathrm{C}\right)$ and wind speed $\left.(\mathrm{m} / \mathrm{s})\right)$. In particular, we calculated NDVI, using the values of red band and the near infrared band surface reflectance acquired by the Landsat 8 , while the variables related to the topology (slope, aspect, height) were obtained from the province's digital elevation model (DEM), and distances to roads and residential areas were extracted from the national topographic and land use map, respectively.

In addition, we obtained climate data of temperature, wind and precipitation from the climate forecast system. In this paper, we used data from previous forest fires as a basis for updating an inventory map of forest fire in the study region. It, used together with the aforementioned ten factors from the Artificial neural network (ANN) model to generalize a function valid across the map that starting from the position information in the map of the single pixel predict the information on its fire/not-fire characteristics.

In the present research regarding the inventory map, a total of 467 fireplaces (historic sites) recorded in 2018 have been counted to date; We use a part of them to train $(327,70 \%)$, and a part $(140,30 \%)$ to validate the model.

Obviously, all these data populate a GIS suitably prepared on ArcGIS that works as input for the data described, and can be updated thanks to the proposed neural network methodology and which ultimately allows to identify in the map the different areas with future potential fire (see Figure 15).

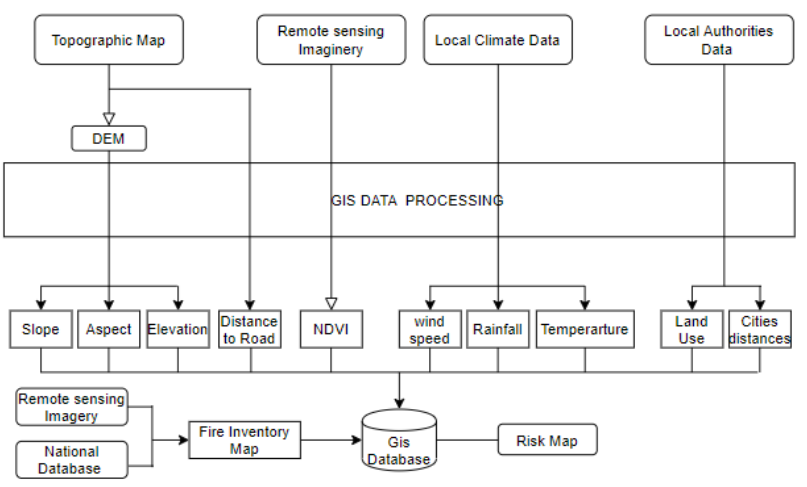

Figure 15. GIS Data processing

The proposed methodology count five main steps: (1) Training; (2) Model design; (3) Optimization (4) Feature measurement and (5) Generation of the fire hazard map of the study area.

\subsection{Training and Model design}

In the model training phase, a weight value is assigned to each factor which influences and contributes to the spread of the fire; each weight expresses the importance and the relevance of the factors. A high weight clearly indicates a high relevance in the process of the fire spreading.

Once that the weights were assigned, W1 and W2 (the weight matrices) are made and then introduced on the Ann's model.

$W_{I}$ is an $\mathrm{N}_{\mathrm{R}} \times \mathrm{N}_{\mathrm{I}}+1$ matrix where $\mathrm{N}_{\mathrm{R}}$ and $\mathrm{N}_{\mathrm{I}}$ are the number of neurons in the hidden layer and the number of input neurons, respectively. Note that the column number of $W_{I}$ is $\mathrm{N}_{I}+1$ to account for a distortion vector. In the specific case, $\mathrm{N}_{\mathrm{I}}=10$ (number of factors chosen that influence the forest fire).

The choice of the number of neurons in the hidden layer was made accurately in such a way that it was not too large (causing 
overfitting) or too small (causing problem in the learning phase).

Selected the number of neurons in the imput $\left(\mathrm{N}_{\mathrm{I}}=10\right)$ and output $\left(\mathrm{No}_{\mathrm{O}}=2\right)$ layer, the number of neuros was set in a way to not exceed $1.5 \times \mathrm{N}_{\mathrm{I}}$ avoiding the oversize that can occur and also avoiding complex Ann model that can be difficult to train. In this case study $\mathrm{N}_{\mathrm{R}}$ was selected to be 10 .

Furthermore, $W_{2}$ is an $N_{O} \mathrm{x} N_{R}+1$ matrix. Therefore, the total number of variables to be optimized is $N_{R} \times N_{I}+N_{O} \times N_{R}+$ 2.

\subsection{Model optimization using the DFP algorithm and the mini-batch algorithm}

As it is known, a metaeurystic algorithm can crash while training a complex Ann model. To work around this situation, a mini-batch back propagation was used to optimize the results. The model was developed in a MATLAB environment.

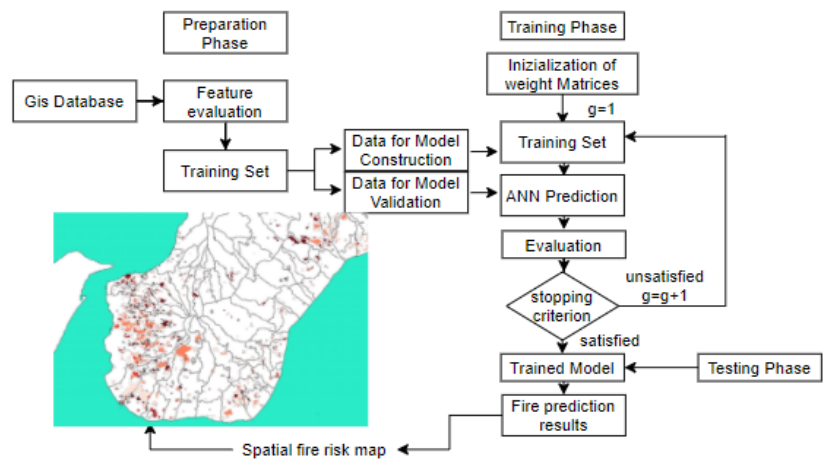

Figure 16. GIS implementation phase

All the solutions are randomly generated, at the first generation $(\mathrm{g}=1)$, within the search domain of $[-10,10]$. The Ann model is then optimized by DFP with the maximum generation number $=1000$. To fend off stagnation and speed up the optimization process, mini-batch backpropagation is activated for the currently best solution. The optimization process was speed up through the backpropagation that is executed once every 100 generations. The maximum number of backpropagation runs is 10. The number of backpropagation training epochs is fixed at 1000 . The batch size is set to $10 \%$ of the training set.

\subsection{Forest fire danger space map generation}

The model, after the training and quality measurement phase, was used to calculate spatial fire hazard indices for all pixels in the study area. The fire hazard indices were then exported in a raster format to generate a spatial map of forest fire danger in the study area.

NDVI is the dominant factor and strongly influences the risk of fire, in fact it reflects the state of the vegetation in a place. The distance from the residential area is the second important factor. A spatial statistics of the fire data must be created, with the spatial analysis of the frequency of the fires by class of slope and altitude, exposure of the slope, forest category and land use, and distance from the roads.

With the help of GIS, a fire risk assessment methodology based on the environmental and anthropic characteristics of the municipal area must be developed and applied, according to the phases described below:

- Identification of significant environmental and anthropic factors for the purposes of fire risk, through bibliographic analysis and evaluation of previous fires;
- Aggregation of factors according to a logical knowledgeprocessing scheme;

- Application of the evaluation model.

Determining the risk of forest fires presupposes knowledge of the conditions of the fuel (vegetation and plant residues), linked to:

- Climatic conditions (atmospheric precipitation, wind speed and duration, solar radiation, relative humidity and air temperature),

- Stationary characters (slope, exposure, position, rockiness),

- Vegetable fuel conditions (species present, age, form of government and treatment, structure and coverage, vegetative stage, phytosanitary status, quantity and degree of decomposition of the ground vegetation).

Characteristics of the evaluation model are:

- Versatility and adaptability

- Forecasting capacity

- Simplicity of the structure of the analysed database

- Structural simplicity (knowledge trees)

- Logical and conceptual rigor

\section{CONCLUSIONS}

With techniques that take into account the NBR and BAI vegetation indices used within the object-based classification, the Structural methodology (Pesaresi, 2000) can be the basis of integrated systems for the creation and updating of the register of areas covered by fire and for monitoring the territory. This also under the aspect of the fight against forest fires, rapidly populating the GIS with territorial data and allowing the realization direct vector maps. The integration with the aid of decision criteria for the discrimination of particular characteristics of the burned areas will complete the systems thus constructed for fighting forest fires that can be also integrated with additional monitored data for allowing a realtime analysis of the fire risk throughout the territory.

Moreover, OBIA proves useful in extracting satellite images of road networks remained accessible after emergencies (Barrile, Bilotta, 2016). In recent years, as regards Remote Sensing in the fight against forest fires, there is a growing interest in the combined use of different sensors, optical and radar data, LIDAR data and passive optical images, including those obtained using Unmanned Aerial Vehicles (UAV), which are able can closely monitoring places of difficult or dangerous access. In recent years, dedicated fire sensors have been developed. Now, the use of LIDAR on post-fire regeneration is still mainly on a local scale but also future satellite LIDAR systems could help improve the answers to the great problem of post-fire hazard assessments

\section{REFERENCES}

Akay, A.E. and Erdoğan, A., 2017: Assessment of Fire Watch Towers by using Visibility Analysis: The Case of Dursunbey, Balıkesir. ISFOR 2017 International Symposium on New Horizons in Forestry, 18-20 October, Isparta, Turkey.

Angiulli, G., Barrile, V., Cacciola, M.: 2005a. M-SVM SAR Images Classification: Experimental Results and Validations. Rivista Italiana di Telerilevamento, 32, 79-86.

Angiulli, G., Barrile, V., Cacciola, M.: 2005b. SAR Imagery Classification Using Multi-Class Support Vector Machines. 
JEWA, 19(14), 1865-1872, and in: Proceedings of PIERS 2005, Hangzhou, China, August 2005, 218-222.

Baatz, M., Benz, U., Dehgani, S., Heynen, M., Höltje, A., Hofmann, P., Lingenfelder, I., Mimler, M., Sohlbach, M., Weber, M., Willhauck, G.: 2004. eCognition 4.0 professional user guide. Definiens Imaging $\mathrm{GmbH}$, München.

Barrile, V., Bilotta, G.: 2007a. Metodologie "Strutturali" su immagini Satellitari per l'analisi Urbana e Territoriale. In: XI ASITA 2007, Torino (Italy), 267-272.

Barrile, V., Bilotta, G.: 2007b. An application of object-oriented analysis to very high resolution satellite data on small cities for change detection. In: Proceedings of 3rd WSEAS (World Scientific and Engineering Academy and Society) Conference on Remote Sensing (Remote '07), Venice, November 21-23, 2007. Recent Advances in Electrical Engineering, 98-103, ISBN: 978-960-6766-18-3, ISSN: 1790-5117, Venice, 21$23 / 11 / 2007$

Barrile, V., Bilotta, G.: 2008. An application of Remote Sensing: Object oriented analysis of satellite data. Int. Arch. Photogramm. Remote Sens. Spatial Inf. Sci., 107-114.

Barrile, V., Bilotta, G.: 2016. Fast extraction of roads for emergencies with segmentation of satellite imagery. Procedia: Social \& Behavioral Sciences, 223, 903-908, ISSN: 1877-0428, doi: 10.1016/j.sbspro.2016.05.313.

Barrile, V., Bilotta, G., Pannuti, F.: 2008. A Comparison Between Methods - A Specialized Operator, Object Oriented and Pixel Oriented Image Analysis - To Detect Asbestos Coverages in Building Roofs using Remotely Sensed Data. Int. Arch. Photogramm. Remote Sens. Spatial Inf. Sci., XXXVII, 427-434.

Barrile, V., Bilotta, G., Meduri, G.M.: 2013. An application of object-based analysis of satellite imagery on waste. In: Towards Horizon 2020 - Proceedings of 33rd EARSeL Symposium; Matera, Italy, 3-6 June 2013. 791-798, Matera: EARSEL, ISBN: 978-88-896933-4-6, Matera, 03/06/2013 - 06/06/2013.

Barrile, V., Cacciola, M., Versaci, M.: 2006a. A Minimal Fuzzy Entropy Model for Pattern Recognition: Evaluation in a SAR Imagery Application. In: Proceedings of 5th WSEAS International Conference on Artificial Intelligence, Knowledge Engineering, Data Bases, AIKED 2006, Madrid, Spain, 275279 .

Barrile, V., Cacciola, M., Versaci, M.: 2006b. Fuzzy Classification with Minimal Entropy Models to Solve Pattern Recognition Problems: A Compared Evaluation in SAR Imagery, WSEAS Transactions on Information Science and Applications, 4(03), 860-867.

Benediktsson, J.A., Pesaresi, M., Arnason, K.: 2003. Classification and Feature Extraction for Remote Sensing Images from Urban Areas Based on Morphological Transformations, IEEE Transactions on Geoscience and Remote Sensing, 41(9).

Bilotta, G.: 2005. Metodologie avanzate applicate allo studio dell'uso della terra. Carto Graphica, 12, 21-24, ISSN: 19742177.
Cecamore, P., Di Federico, A., Paolini, S.: 2004. Servizi di osservazione delle aree incendiate: le esperienze europee nel progetto GMES RISK-EOS. In Atti della 8a Conferenza Nazionale ASITA, Roma.

Chirici, G., Corona, P., Travaglini, D.: 2003. Sperimentazione di tecniche di classificazione object-oriented di immagini QuickBird a fini forestali. In: L'Italia Forestale e Montana, 4 , Atti del Workshop "Utilizzo di dati telerilevati per le statistiche di copertura del suolo negli ambienti forestali", Firenze.

Csiszar I.,. Schroeder W, Giglio L., Ellicott E., Vadrevu K.P., Justice C.O., Wind B. 2014 Active fires from the Suomi NPP Visible Infrared Imaging Radiometer Suite: product status and first evaluation results. in: J. Geophys. Res. Atmos., 119, pp. 803-816,

Daldegan G.A., Carvalho Júnior O.A., Guimarães R.F., Gomes R.A.T., Ribeiro F.F., McManus C. 2014. Spatial patterns of fire recurrence using remote sensing and GIS in the Brazilian savanna: Serra do Tombador Nature Reserve, Brazil. In: Remote Sens., 6, pp. 9873-9894

Hislop, S.; Jones, S.; Soto-Berelov, M.; Skidmore, A.K.; Haywood, A.; Nguyen, T. Using Landsat Spectral Indices in Time-Series to Assess Wildfire Disturbance and Recovery. Remote Sens. 2018, 10, 460.

ITALSCAR: 2003. Burned Forest Mapping from Space - An Earth Observation service demonstration project in Italy funded by the Data User Programme of the European Space Agency requested by the Italian Civil Protection Authorities, Roma.

Kucuk, O., Topaloglu, O., Altunel, A.O. and Cetin, M., 2017: Visibilty analysis fire lookout towers in the Boyabat state forest enterprise in Turkey, Environmental Monitoring and Assessment, 189(2017):329.

Lentile L.B., Holden Z.A., Smith A.M.S., Falkowski M.J., Hudak A.T. 2006.Remote Sensing Techniques to Assess Active Fire Characteristics and Post Fire Effects. In USDA Forest Service/UNL Faculty Publications, pp. 319-345

Marzano, R., Bovio, G.: 2004. Analisi dell'interfaccia urbanoforesta mediante dati telerilevati per la caratterizzazione del rischio di incendio boschivo- In: Atti della 8 a Conferenza Nazionale ASITA, Roma.

Mitri, G.H., Gitas, I.Z.: 2006. Fire type mapping using objectbased classification of Ikonos imagery. International Journal of Wildland Fire, 15, 457-462.

Soille, P., Pesaresi, M.: 2002. Advances in Mathematical Morphology Applied to Geoscience and Remote Sensing. IEEE Transactions on Geoscience and Remote Sensing, 40(9).

Quinta-Nova, L. Fernandez, P. and Nuno, P., 2017: GIS-Based Suitability Model for Assessment of Forest Biomass Energy Potential in a Region of Portugal, World Multidisciplinary Earth Sciences Symposium (WMESS 2017),

White, J.C.; Wulder, M.A.; Hermosilla, T.; Coops, N.C.; Hobart, G.W. A nationwide annual characterization of 25 years of forest disturbance and recovery for Canada using Landsat time series. Remote Sens. Environ.

2017, 194, 303-321. 